\title{
PENELUSURAN IDENTITAS BUDAYA NUSANTARA DALAM TEKS BERBAHASA INGGRIS
}

\author{
Ina Sukaesih ${ }^{1}$, Yoyok Sabar Waluyo ${ }^{2}$ dan Rd Safrina ${ }^{3}$ \\ ${ }^{1}$ Jurusan Akuntansi, Politeknik Negeri Jakarta \\ ${ }^{2}$ Jurusan Teknik Informatika dan Komputer, Politeknik Negeri Jakarta \\ ${ }^{3}$ Fakultas Pendidikan Bahasa dan Sastra, Universitas Pendidikan Indonesia \\ Email : ${ }^{\text {ina.sukaesih@akuntansi.pnj.ac.id, }{ }^{2} \text { yoyok.sw@tik.pnj.ac.id, }{ }^{3} \text { safrina@upi.edu }}$
}

\begin{abstract}
This paper addresses the English translation of specific Sundanese cultural references in the English Translation of selected Sundanese short stories. The issue of translatability is highlighted as the paper explores the nuances of possible meanings from the selected words. The content analysis on Watson's English translations of selected Sundanese short stories in "Neng Maya" is framed by theoretical propositions from Molina \& Albir's translation techniques and Nababan's translation quality assessment. Using the methods of Spradley procedure, it is revealed that the language units found in the source texts re words and phrases, while in the target texts, clauses are also found. The types of cultural words exist in the short stories are: words of emphasis, verbs, nouns, and adverbs. The translation techniques mostly used are deletion, equivalence, modulation, reinforcement, literal, and amplification. The techniques used by the translator have led to lack of translation quality, specifically the accuracy aspect.
\end{abstract}

Key words: cultural references, translatability, translation techniques, translation quality

\section{Abstrak}

Paper ini menyampaikan hasil penelitian tentang penerjemahan ungkapan bermuatan budaya dari beberapa cerita pendek berbahasa Sunda dalam bahasa Inggris. Masalah 'intranslatability' disoroti berdasarkan eksplorasi kemungkinan nuansa makna dari kata-kata yang dipilih. Analisis konten terhadap terjemahan cerita pendek dari kumpulan cerita pendek 'Neng Maya' yang dikerjakan oleh C.W. Watson merujuk pada teori teknik penerjemahan yang diusulkan Molina\&Albir dan teori Asesmen kualitas terjemahan dari Nababn dkk. Dengan menggunakan tahapan prosedur Spradley, dalam cerita pendek yang dipilih, terdapat beberapa tipe ungkapan bermuatan budaya, yaitu: kata penegas, kata kerja, kata benda, dan kata keterangan. Sementara unit Bahasa yang digunakan dalam teks sumber adalah kata dan frasa dan dalam teks sasaran kata, frasa dan klausas. Teknik penerjemahan yang dominan digunakan adalah deletion, equivalence, modulation, reinforcement, literal, dan amplification. Penggunaan teknik yang didominasi dengan deletion menyebabkan kurangnya kualitas terjemahan, khususnya keakuratan.

Kata Kunci: ungkapan bermuatan budaya, translabilitas, teknik penerjemahan, kualitas terjemahan.

\section{PENDAHULUAN}

\section{Latar Belakang}

Dalam proses komunikasi penyampaian pesan melibatkan faktor-faktor kebahasaan dan budaya. Faktor kebahasaan terdiri dari unit bahasa: kata, frasa, dan klausa. Sementara budaya dapat dilihat dari sikap dan penggunaan unit bahasa yang diungkapkan secara eksplisit dan implisit.
Penggunaan bahasa implisit yang dipengaruhi oleh budaya yang berbeda tidak mudah untuk di transfer. Di Indonesia, walaupun bahasa pemersatu adalah bahasa Indonesia, tetapi bahasa ibunya berbedabeda tergantung dari suku masing-masing. Bahasa Sunda yang digunakan sebanyak 42 juta (Wikipedia, 2016) di area Jawa barat dan Lampung serta beberpa daerah 
transmigrasi di luar pulau Jawa merupakan bahasa yang memiliki 'undak usuk basa' (perbedaan tingkat bahasa). Hal ini diperlihatkan dengan penggunaan kata yang berbeda yang digunakan untuk sendiri, atau berbicara dengan orang tua, dengan teman, dan sebagainya. Contohnya bisa dilihat di bawah ini:

“Teh Nining tos uih?.'(Lestari, 2014)

Dari contoh dapat dilihat bagaimana kata 'teh' digunakan untuk menyapa perempuan yang lebih tua dari pembicara, bisa saudara atau bukan. Penggunaan kata itu mencerminkan rasa hormat; kata 'teh' salah satu kata yang mengandung pesan budaya. Terjemahannya dalam bahasa Inggris, menjadi:

“Nining, you're home," she said her voice all of tremble.

Terjemahan unsur kata sapaan 'teh' dari teks sumber (Tsu) luruh, tidak terlihat, tidak ada ekuivalennya dalam teks sasaran (Tsa). Jadi dapat disimpulkan disini bahwa pesan budaya dari Tsu tidak tersampaikan dalam Tsa. Hasil terjemahan seharusnya memiliki kualitas terjemahan dengan memenuhi aspek keakuratan pesan, keberterimaan dan keterbacaan. Sementara penerjemahan berfungsi mentransfer pesan dari Tsu ke Tsa. Jelas dalam terjemahan itu terdapat distorsi makna karena makna implisit dari kata 'teh' tidak tersampaikan.

Sementara terjemahan merupakan transfer antar budaya dalam Tsu ke dalam Tsa. Jadi terjemahan bukan hanya menekankan pada translatabilitas dari Tsu tetapi juga harus mampu mentransfer sekatsekat budaya atau ungkapan yang bermuatan budaya secara jelas dan tepat.Seorang penerjemah dalam upaya memperoleh terjemahan yang baik memerlukan keterampilan, pengetahuan dan praktek penerjemahan yang memadai.

Dari penjelasan penerjemah di atas dapat disarikan bahwa penerjemahan dari bahasa Sunda ke dalam bahasa Inggris dikategorikan sulit. Kesulitan ini mencakup beberapa faktor, yaitu kesulitan untuk memperoleh terjemahan yang akurat karena yang ditransfer bukan hanya makna yang terkandung (secara eksplisit) tetapi juga 'tone' atau rasa di dalamnya (arti implisit) yang mengandung emosi yang dibangun penulis dalam karakter cerita. Emosi ini yang diharapkan sama dengan yang dimiliki pembaca. Sementara itu karena perbedaan budaya, emosi yang diharapkan dari pembaca yang memiliki budaya berbeda, tidak akan sama. Ketidaksamaan emosi ini yang merupakan faktor yang membuat penerjemahan sulit karena perbedaan rasa, emosi dan kesan psikologis yang berbeda. Dan ditegaskan oleh penerjemah bahwa tingkat keterbacaan(kepahaman pembaca) terjemahan akan lebih baik dengan pengetahuan dan keterampilan penerjemah dalam menerjemahkan karya sastra dari bahasa lain(bahasa Sunda) ke dalam bahasa Inggris.

Untuk menjembatani 'gap' kesulitan dalam menerjemahkan karya sastra khususnya, dan penerjemahan dari bahasa Sunda ke dalam bahasa Igggris, diperlukan model untuk praktek menerjemahkan karya sastra dan lebih khusus dalam unit bahasa yang mengandung pesan budaya. Akan tetapi sebelum menyusun model, unit bahasa yang digunakan dalam teks sumber dan teks sasaran harus dianalisa; teknik penerjemahan yang diterapkan oleh penerjemah harus diteliti untuk mengetahui pengaruh penggunaan teknik penerjemahan terhadap kualitas terjemahan.

Dengan tujuan memperoleh model yang dapat dijadikan acuan untuk menerjemahkan karya sastra, khususnya ungkapan yang bermuatan budaya dari Bahasa Sunda ke dalam Bahasa Inggris, beberapa cerita pendek dari kumpulan cerita pendek "Neng Maya' dan terjemahannya dalam kumpulan cerita pendek “Miss Maya' digunakan sebagai bahan analisis. Cerita pendek itu berjudul:Korupsi karya Aan Merdeka Permana; Terjemahannya: Corrupt karya 
C.W. Watson; Ditigas Gurating Takdir karya Hena Sumarni; Terjemahannya: Decided by A Stroke of Fate karya C.W. Watson; Pamajikan karya Erwin Wahyudi; Terjemahannya: My Wife karya C.W. Watson; Isukan Ulang Taun karya Fitria Puji Lestari; $\quad$ Terjemahannya: Birthday Tomorrow C.W. Watson.

Karya terjemahan cerita pendek dimaksud dianalisa menggunakan teori yang diusulkan oleh para ahli. Untuk teori ungkapan yang mengandung makna budaya digunakan kategori Molina yang diringkas oleh $\mathrm{Ku}$ menjadi empat kategori: (1) Environment, including ecology, place names, etc.; (2) Cultural heritage (religious beliefs, historical events, characters, festivities, folklore, housing, objects, etc.; (3) Social culture (conventions, beliefs, habits, social organizations, etc.;(4) Linguistic culture (fixed expressions, idioms, insults, etc.(Guerra, 12/2012). Teknik penerjemahan yang diterapkan unruk analisis data terjemahan adalah teknik yang diusulkan oleh Molina\&Albir dengan kategori literal dan oblique translation tqchniques(Molina\&Albir, 2002). Sementara untuk menganalisa kualitas terjemahan, gagasan Nababan dkk. tentang kualitas terjemahan dengan aspek keakuratan makna, keberterimaan dan keterbacaan digunakan(Nababan, 2012). Dalam kesempatan ini hanya aspek keakuratan yang digunakan untuk melihat apakah makna ungkapan bermuatan budaya dapat tersampaikan atau tidak dalam karya terjemahannya. Sementara tata bahasa bahasa Sunda mengacu pada penjelasan dalam buku Tata Basa Sunda Kiwari(Yayat Sudaryat, 2013).

\section{Rumusan Masalah}

Rumusan masalah yang diangkat dalam penelitian ini adalah: a) Bagaimana model penerjemahan ini dapat membantu menerjemahkan unit bahasa yang mengandung pesan budaya dengan baik sehingga dapat menghasilkan karya terjemahan yang berkualitas? b) Bagaimana model penerjemahan ini dapat membantu dalam proses penerjemahan, khususnya penggunaan teknik atau strategi penerjemahan yang tepat untuk unit Bahasa yang mengandung pesan budaya? c) Bagaimana model penerjemahan dapat digunakan untuk menghasilkan terjemahan yang dapat memperlihatkan identitas budaya dalam teks bahasa sumber?

\section{Tinjauan Pustaka}

Penerjemahan memiliki fungsi transfer pesan, ilmu pengetahuan, teknologi dan budaya. Fungsi transfer harus disertai dengan keakuratan makna atau pesan yang disampaikan, kepatuhan terhadap aturan kebahasaan dalam Bahasa sasaran dan mempertimbangkan tingkat pemahaman pembaca yang merupakan sasaran akhir dari produk terjemahan (Nababan dkk, 2012:46). Dalam era globalisasi dimana intensitas komunikasi sangat tinggi dalam segala bidang, komunikasi menggunakan satu bahasa yang mampu menjembatani kepentingan kedua belah pihak diperlukan. Satu bahasa yang secara global digunakan adalah bahasa Inggris. Untuk itu perlu dipelajari dan diasah bagaimana penerjemahan dari bahasa yang merupakan mother tongue atau bahasa ibu ke dalam bahasa Inggris.

Penerjemahan adalah pemindahan pesan dari bahasa sumber ke dalam bahasa sasaran. Pesan yang diterjemahkan harus memiliki kesepadanan antara pesan dari bahasa sumber (Bsu)dan pesan yang telah dialihkan ke dalam bahasa sasaran (Bsa). Dari kutipan berikut:' it is rendering the meaning of a text into another language in the way that the author intended the text'. (Newmark, 1988). Sejalan dengan Newmark, juga Catford menyatakan: "Translation may be defined as the replacement of textual material in one language (SL) by equivalent textual material in another language (TL)(Catford, 
1965)”.Dalam penerjemahan, pesan yang dialihkan harus sesuai dengan makna yang diungkapkan oleh penulis atau pembicara Bsu. Makna yang diungkapkan mungkin memiliki makna yang sesuai dengan katakata atau ujaran yang disampaikan(ideasional), tetapi mungkin juga makna yang lebih dari apa yang ditulis atau diucapkan(interpersonal). Hal ini bisa terjadi karena penulis atau pembicara Bsu memiliki lingkup kebiasaan, pandangan, norma sosial tersendiri yang mungkin berbeda dengan penerjemah. Jika seperti itu, seorang penerjemah harus memahami bukan saja arti ungkapan yang tersurat, tetapi juga makna tersirat, makna yang dipengaruhi oleh kebiasaan, pengalaman, dan norma sosialnya.

\section{Ideologi, Teknik dan Kualitas Terjemahan}

Dalam penerjemahan, ideologi dimaksud adalah keyakinan seorang penerjemah dalam melakukan penerjemahan, bahwa yang dilakukan dalam proses penerjemahan merupakan hal yang benar yang menghasilkan produk penerjemahan dengan kualitas yang baik. Sementara teknik penerjemahan adalah cara yang digunakan oleh penerjemah ketika sudah berhadapan dengan bahan yang akan diterjemahkannya. Kualitas terjemahan adalah tingkat kesesuaian dari hasil terjemahan dengan pesan yang dalihkan dari teks bahasa sumber. Ideologi, teknik penerjemahan dan kualitas terjemahan sangat berkaitan karena ideologi dan teknik akan mempengaruhi kualitas terjemahan.

Teknik penerjemahan memiliki istilah lain sesuai dengan kepercayaan ahli, misalnya Molina\&Albir menggunakan istilah teknik sementara ahli lain menggunakan prosedur atau strategi. Dalam penelitian ini, teknik penerjemahan yang diajukan oleh Molina\&Albir yang akan digunakan. Molina\&Albir mengajukan 18 teknik yang telah merangkum prosedur dan strategi dari ahli-ahli sebelumnya.

Kualitas terjemahan dijabarkan ke dalam aspek keakuratan, keberterimaan dan keterbacaan. Kualitas terjemahan yang telah menggabungkan antara unsur kualitatif dan kuantitatif adalah asesmen kualitas terjemahan yang diajukan oleh Nababan dkk. Teknik penerjemahan dan Asesmen Kualitas Terjemahan akan digunakan sebagai alat dalam metode penelitian.

\section{METODE PENELITIAN}

Metode yang digunakan dalam penelitian bidang penerjemahan ini adalah metode kualitatif deskriptif dimana data yang diperoleh dideskripsikan secara mendalam untuk memperoleh gambaran rinci tentang fenomena linguistik yang diteliti. Dalam penelitian kualitatif data diperoleh langsung dari bahan kajian, yang dikenal dengan istilah purposive sampling dimana tujuanpenelitian ditentukan terlebih dahulu dan data dipilih sesuai kriteria yang telah ditetapkan tanpa menggunakan istilah populasi dan sampel. Data yang dituju pada penelitian ini adalah ungkapan yang mengandung makna budaya dari sumber bahan kajian yang telah ditetapkan yang diambil dari seluruh bagian cerita pendek, yaitu: Abstract, Orientation, Complication, Evaluation, Resolution, dan Coda(Tri Wiratno, 2011). Sementara tahapan atau prosedur yang dilalui dalam analisa data adalah prosedur Spradley dengan tahapan analisis domain, analisis taksonomi, analisis komponensial dan analisis tematis. Dalam Lee dinyatakan bahwa "Spradley includes four analytic process: domain, taxonomic, componential, and thematic" (Lee \& Vanashri, 2011). Data yang digunakan dikategorikan menjadi dua, yaitu data linguistik dan data terjemahan. Data linguistik berupa ungkapan yang mengandung budaya, baik dari Tsu maupun Tsa, sementara data terjemahan adalah 
teknik penerjemahan yang digunakan dan kualitas terjemahan. Untuk menjaga validasi, dilakukan trianggulasi data dan metode pengumpulan data. Validasi data dilakukan dengan pengambilan data dari bahan kajian yang ditetapkan serta pendapat penerjemah dan ulasan dalam karya terjemahan. Sementara validasi metode pengumpulan data dilakukan dengan metode wawancara mendalam, pengisian kuesioner oleh raters dan FGD.

\section{HASIL DAN PEMBAHASAN}

Unit linguistik yang ditemukan dalam Tsu adalah kata dan frasa, sementara dalam terjemahannya selain kata dan frasa ditemukan juga klausa. Dari analisis yang telah dilakukan terhadap bahan kajian dengan teori yang diterapkan. Berikut adalah rincian temuan ungkapan bermuatan budaya yang dituangkan dalam tabel di bawah ini.

Tabel 1. temuan ungkapan bermuatan budaya

\begin{tabular}{|l|l|l|l|l|l|}
\hline Cerpen & ON & KP & KK & KS & KKt \\
\hline Korupsi & 1 & 38 & 5 & 5 & 2 \\
\hline DGT & 8 & 18 & 9 & 3 & 5 \\
\hline Pam. & 15 & 0 & 7 & 3 & 13 \\
\hline IUT & 18 & 9 & 31 & 2 & 30 \\
\hline & 42 & 65 & 52 & 13 & 50 \\
\hline
\end{tabular}

\section{Unit Linguistik}

Dari tabel dapat dilihat bahwa ungkapan yang berbentuk onomapoetic berjumlah 42, kata penegas 65, kata kerja 52, kata sifat 13, kata keterangan 50, sementara tidak ada ungkapan yang berbentuk kata benda. Jumlah keseluruhan ungkapan sejumlah 222. Jika diambil prosentase, onomapoetic 18,91\%, kata penegas 29,27\%, kata kerja 23,42\%, kata sifat 5,85\%, dan kata keterangan 22,52\%. Seluruh onomapoetic dan kata penegas merupakan unit linguistik kata; Sementara kata kerja yang ditemukan dalam Tsu, 20 berbentuk kata dan 11 berbentuk frasa. Kata sifat lebih banyak berbentuk kata, 10, dan dua berbentuk frasa. Dalam kata keterangan, penggunaan kata dan frasa cukup berimbang, dari 29 yang terdapat dalam Tsu, 15 berbentuk kata dan 14 berbentuk frasa. Bentuk unit linguistik dari Tsu pada umumnya diterjemahkan ke dalam unit linguistik yang sama. Beberapa unit linguistik kata dari Tsu diterjemahkan menjadi bentuk frasa atau klausa, di sini terjadi perubahan kategori unit linguistik, tetapi jumlahnya tidak terlalu signifikan, hanya sekitar 2\%. Contohnya: "Enya euy?' diterjemahkan menjadi "Could it be true?", dari kata berubah menjadi klausa; dan "genjrang-genjreng..." diterjemahkan menjadi "no sound of a guitar..." dari kata berubah menjadi frasa.

Persamaan kategori unit linguistik dari Tsu ke dalam Tsa tidak dapat dihindari untuk onomapoetik dan kata penegas. Namun, perubahan yang dilakukan untuk tetap setia pada makna yang terkandung dalam Tsu, dari kata ke dalam frasa atau klausa merupakan upaya yang maksimal, walaupun tidak selalu berhasil dengan mulus. Unit linguistik yang digunakan dalam menerjemahkan kata kerja, kata sifat dan kata keterangan relatif stabil, tidak berubah dari unit linguistic yang digunakan dalam Tsu. Dari pengamatan dapat ditarik pelajaran bahwa dalam menerjemahkan diupayakan untuk mencari padanan ungkapan yang sesuai dengan unit linguistik Tsu, walaupun tidak seluruh ungkapan memiliki padanan; hal ini dapat diupayakan dengan menggunakan perubahan kategori (unit shift) yang dapat lebih mendekati makna sesungguhnya dari Tsu.

\section{Teknik Penerjemahan}

Teknik penerjemahan yang digunakan dalam menerjemahkan linguistic culture yang terdapat pada empat cerita pendek dari bahasa Sunda ke dalam bahasa Inggris ada 10, yaitu deletion, modulation, reinforcement, amplification, reduction, equivalence, transposition, literal, generalization dan concentration. Teknik penerjemahan Deletion digunakan sebanyak 
25 kali (13.6\%); Modulation 28 kali (15.22\%); Reinforcement 23 kali (12.5\%); Amplification 28 kali (15.22\%); Reduction 5 kali (2.7\%); Equivalence 61 kali (33.2\%); Transposition 9 kali (4.9\%); Literal 4 kali (2.8\%); Generalization 1 kali (0.5\%); dan Concentration 1 kali (0.5\%).

Dari urutan persentase penggunaan teknik penerjemahan tertinggi, dapat diurutkan sebagai berikut: Equivalence (33.2\%); Modulation dan Amplification, masing-masing (15.22\%); Deletion (13.6\%); Reinforcement (12.5\%); Transposition (4.9\%); Literal (2.8\%);Reduction (2.7\%);Generalization dan Concentration, masing-masing (0.5\%). Fakta ini memperlihatkan bagaimana penerjemah berupaya sebaik mungkin mencari padanan untuk ungkapan yang diterjemahkannya. Ketika padanan tidak ditemukan, upayanya adalah memberikan deskripsi yang memperjelas makna dari ungkapan bermuatan budaya, oleh karena itu, teknik modulasi dan amplifikasi digunakan. Teknik deletiondan reduction relatif sering digunakan dalam menerjemahkan onomapoetic dan kata penegas. Hal ini didorong oleh keunikan onomapeotic dan kata penegas dalam bahasa Sunda, yang tidak banyak padanannya dalam bahasa lain, bahkan dalam bahasaIndonesia sebagai bahasa nasional. Fakta tersebut tidak banyak memberikan pilihan pada penerjemah, hal inilah yang merupakan salah satu elemen budaya bahasa Sunda yang dapat dikategorikan dalam intranstabilitas dalam penerjemahan. Begitu juga penggunaan teknik generalisasi dan konsentrasi, generalisasi digunakan ketika terdapat padanan yang minim dalam Tsa, dan konsentrasi digunakan ketika digunakan karena terdapat padanan dalam Tsa yang menggunakan kata-kata lebih sedikit daripada Tsu.

Pada umumnya dapat disimpulkan bahwa teknik penerjemahan telah diberdayakan secara maksimal oleh penerjemah.
Walaupun begitu, kualitas terjemahan belum maksimal. Hal ini mungkin dipengaruhi oleh faktor-faktor lain, seperti yang sering diungkapkan bahwa kompetensi penerjemah dalam kedwibahasaan, kemampuan mentransfer dari Tsu ke dalam Tsa, pengetahuan budaya Bahasa sumber dan Bahasa sasaran merupakan faktor-faktor lain yang dapat mempengaruhi keberhasilan dalam terjemahan.

\section{Kualitas Terjemahan}

Kualitas terjemahan memiliki tiga aspek yang saling berkaitan yang bermuara pada baik dan buruknya kualitas terjemahan, yaitu: aspek keakuratan, keberterimaan, dan keterbacaan (Nababan, 2012). Mengingat penerjemah merupakan seorang 'native speaker'bahasa Inggris sebagai Tsa, di sini peneliti mengasumsikan bahwa aspek keberterimaan merupakan aspek yang tidak perlu diragukan lagi, dan begitu pula dengan aspek keterbacaan. Oleh karena itu, aspek yang dibahas dalan penelitian ini adalah aspek keakuratan (accuracy). Keakuratan di sini mengacu pada seberapa akurat makna yang dilihat dari terjemahan ungkapan yang mengandung budaya dari bahasa Sunda ke dalam bahasa Inggris pada empat cerita pendek.

Dari analisis penggunaan teknik penerjemahan dan kualitas terjemahan, dapat dilihat bahwa penggunaan teknik penerjemahan equivalence, amplification, literal, transposition, reinforcement, dan modulation menghasilkan tingkat keakuratan makna dengan skor minimal 2 (dua). Hal ini mengindikasikan bahwa penggunaan teknik-teknik dimaksud berdampak positif terhadap kualitas terjemahan. Sementara penggunaan teknik penerjemahan deletion dan reduction membuahkan hasil rata-rata skor 1 (satu). Dengan kalkulasi antara skor untuk setiap unit linguistic yang terdapat dalam cerita pendek yang merupakan bahan kajian dalam penelitian ini, dapat dilihat bahwa skor rata- 
rata yang diperoleh dalam aspek keakuratan adalah 2.1. yang artinya bahwa sebagian besar makna kata, istilah teknis, frasa, klausa atau kalimat bahasa sumber sudah dialihkan secara akurat ke dalam bahasa sasaran. Namun, masih terdapat distorsi makna atau terjemahan makna ganda (taksa) atau ada makna yang dihilangkan, yang mengganggu keutuhan pesan(Nababan, 2012). Skor ini menurut penulis wajar karena beberapa faktor, yaitu adanya faktor intranstabilitas Tsu antara lain dalam onomatopoetic dan kata penegas yang sangat unik dalam bahasa sunda; selain itu, unsur penerjemah yang seorang 'native' Tsa tentu tidak akan sedalam 'native' Tsu dalam hal pengetahuan budaya Sunda. Hal ini menyebabkan dampak yang terlihat pada kualitas terjemahan aspek keakuratan yang mungkin tidak diharapkan oleh penerjemah sementara minat penerjemah terhadap transfer budaya Sunda sangat kuat. Ha ini dapat disimpulkan dari kata pengantar penerjemah dalam kumpulan cerita pendek hasil terjemahnnya.

\section{KESIMPULAN DAN SARAN}

Penerjemahan sebagai salah satu media pembelajaran budaya satu dengan budaya yang lainnya penting untuk ditelaah dan dipelajari dengan seksama. Penerjemahan referensi budaya dari satu budaya ke dalam budaya lain masih merupakan hal yang menarik diperbincangkan. Walaupun sudah menjadi bahan bahasan yang sering didiskusikan, dan sering menjadi topik penelitian, akan tetapi masih saja ada aspek intranstabilitas yang muncul. Oleh karena itu, hasil penelitian tentang penerjemahan unsur budaya ini patut menjadi titik tolak untuk menjadi dasar suatu model yang mampu mengurai masalah intranstabilitas, khususnya unsur-unsur budaya dalam penerjemahan dari bahasa Sunda ke dalam bahasa Inggris. Dari hasil pembahasan dapat dilihat bahwa terdapat keterkaitan antara unit linguistic, teknik penerjemahan dan kualitas terjemahan. Jadi jelas sekali bahwa seorang penerjemah sebaiknya memiliki pengetahuan dan keterampilan bukan saja ke dwibahasaan, tetapi pengetahuan tentang penerjemahan, dan budaya kedua bahasa sangat penting.

\section{DAFTAR PUSTAKA}

Guerra, A. F. (12/2012). Translating culture: problems, strategies and. a journal of literature, culture and literary translation, 1-26.

Lee, J. S., \& Vanashri, D. (2011). Progressing Through the Haze in Science and Mathematics Education Research: ontemporary Use of Spradley's Qualitative Inquiry in Two case Studies. IJOM.

Lestari, F. P. (2014, Desember). Isukan Ulang Taun. Neng Maya. Bandung, Jawa Barat, Indonesia: PT Pustaka Kiblat Utama.

Molina\&Albir. (2002). Translation Techniques Revisited: A Dynamic and Functionalist Approach. Meta, XLVII(4).

Nababan, N. S. (2012, June). Pengembangan Model Penilaian Kualitas Terjemahan. Kajian Linguistik dan Sastra, 24(1), 3957.

Tri Wiratno, R. S. (2011). Pengantar Linguistik Umum. Jakarta: Penerbit Universitas Terbuka.

Watson, C. (2014, December). Miss Maya. Miss Maya. Bandung, West Java, Indonesia: PT Kiblat Buku Utama.

Wikipedia. (2016, December). Sundanese Language, Native Speakers.

Yayat Sudaryat, A. P. (2013). Tata Basa Sunda Kiwari. Bandung: Yrama Widya. 
Ina Sukaesih dkk

Penelusuran Identitas Budaya... 